\title{
MEZCALES Y DIVERSIDAD BIOCULTURAL EN LOS ALREDEdores del Volcán de Colima. EL CASO DE LOS PRODUCTORES TRADICIONALES de Zapotithán de VAdillo
}

\section{Mezcales AND Biocultural Diversity around the Volcan de Colima. THE CASE OF TRADITIONAL PRODUCERS FROM ZAPOTITLÁN DE VADILLO}

\section{Carlos Lucio ${ }^{1}$}

Resumen: El mezcal de los alrededores del Volcán de Colima pertenece a una gran tradición productora que se sostiene en un amplio conocimiento ecológico tradicional, y en prácticas de manejo de los recursos naturales que demuestran la existencia de un vínculo inextricable entre diversidad biológica y cultural, lo cual constituye un caso ejemplar de diversidad biocultural. Los productores de mezcal en el sur de Jalisco han implementado modalidades de aprovechamiento sustentable en las más de veinte variedades locales de agave, que hacen del occidente de México una de las áreas más importantes para la conservación "in situ" de especies y variedades locales de agave mezcalero. Además el tipo de prácticas agroecológicas de estos productores reflejan claramente la importancia de la cultura indígenacampesina en la conservación de la biodiversidad.

\footnotetext{
${ }^{1}$ Doctor en Ciencias Sociales con especialidad en Antropología Social por el CIESASOccidente. Investigador posdoctoral en la Unidad Académica en Estudios del Desarrollo de la Universidad Autónoma de Zacatecas. Área de especialización: diversidad biocultural, conflictos socioambientales, movimientos indígenas.

Correo electrónico: luccarlos@gmail.com

Fecha de recepción: 2707 15; Fecha de aceptación: 031215.
}

(cc) EY-No-ND Páginas 13-43. 
Palabras clave: biodiversidad, conocimiento biocultural, agave, sur de Jalisco, mezcal.

Abstract: Mezcal from the area surrounding the Colima volcano belongs to a long tradition of production which is maintained by great traditional ecological knowledge, and land management practices that demonstrate the existence of an inextricable link between biological and cultural diversity, constituting an exemplary case of biocultural diversity. Mezcal producers in southern Jalisco have implemented procedures for sustainable use in more than twenty agave local varieties that make western Mexico one of the most important areas for in situ conservation of the agave species and landraces. In addition, the type of agroecological practices of these producers clearly reflect the importance of indigenous-peasant culture in the conservation of biodiversity.

Keywords: biodiversity, biocultural knowledge, agave, southern Jalisco, mezcal.

\section{Introducción}

En los mezcales tradicionales hay una vasta diversidad de aromas y sabores, pero sobre todo una enorme riqueza cultural y gastronómica detrás de su elaboración, no sólo por la numerosa diversidad de especies, sub-especies y variedades de agave con la que se produce la bebida, sino también por la diversidad geográfica y ambiental de donde proviene cada planta. Los distintos ciclos de maduración de los agaves que se utilizan en la producción de mezcal le proveen de enormes diferencias organolépticas, y le otorgan un carácter único y especial a los mezcales producidos dentro y fuera de la Denominación de Origen. Además, las diferentes técnicas y procedimientos tradicionales de producción, cuyo saber-hacer relacionado con la siembra, cosecha, cocción, molienda, fermentación y destilación, custodia celosamente cada maestro mezcalero; amplían significativamente esa diversidad biológica y cultural. 
Otro rasgo, en el mismo sentido, se puede observar en los más de ochocientos nombres comunes con los que se identifican los agaves en México y en las 26 lenguas indígenas con los que se nombran, además del castellano, en cerca de 28 entidades federativas (Colunga, 2006). La bebida también se identifica regionalmente de distintas maneras, como se observa con los términos "raicilla", "tuxca", "sỉkua", "tepe", "bacanora", "comiteco", entre otras denominaciones utilizadas para referirse al mezcal. ${ }^{2}$

La diversidad de los mezcales tradicionales depende de las más de cuarenta especies de agave con los que se elaboran, sin hacer mención de las variedades de cada especie que pueden ser muy numerosas, como en el caso del $A$. angustifolia conocido como el de mayor distribución geográfica en el país, al encontrarse desde Sonora hasta Chiapas y la península de Yucatán. El mezcal se produce en por lo menos veintiséis estados de la República, y esas diferencias geográficas le dotan de una amplísima variedad de sabores, aromas y demás propiedades organolépticas. Por todo lo anterior, se considera la producción de mezcal como una de las cuestiones más relevantes para identificar la riqueza biocultural de los pueblos originarios, y para el caso que nos ocupa esa tradición se expresa con excelencia en el sur de Jalisco, particularmente en los alrededores del Volcán de Colima.

En esta zona, a diferencia de Oaxaca, donde se ubica la provincia florística con mayor abundancia de especies de agave del país, sólo existen dos especies de magueyes mezcaleros ${ }^{3}$ ( $A$. angustifolia Haw y

2La "raicilla" es producida en el estado de Jalisco a partir del agave maximiliana,
inaequidens y valenciana en la zona de Sierra Occidental, y con agave angustifolia y
rhodacantha en la zona costera. El "tuxca" se elabora en el municipio de Tuxcacuesco
y Tolimán en el mismo estado. En Michoacán se nombra como "sïkua" que en lengua
purépecha significa mezcal. El "tepe" se produce con A. durangensis por indígenas
tepehuanos en Canoas, municipio de Mezquital (Durango), comunidad cercana a
los límites de Jalisco y Nayarit. Los indígenas wixárikas (o huicholes) elaboran un
destilado de agave con fines ceremoniales conocido como "tuchi" o "tepe" el cual se
tiene identificado con la especie A. bovicornuta según Faba y Aedo (2003). "Bacanora"
se denomina al destilado producido con A. angustifolia en el estado de Sonora.
Finalmente, se le dice "comiteco" al mezcal producido en Comitán de Domínguez,
Chiapas, con agaves americana y salmiana. Esta muestra no pretende ser exhaustiva,
sino reflejar apenas un poco de la diversidad con la que se conoce a la bebida.
3 "Los magueyes, también conocidos como agaves o mezcales, han sido aprovechados 
A. rhodacantha, Trel.). Sin embargo, a pesar de que la diversidad de especies es muy reducida, la zona del Nevado de Colima destaca por la cantidad de variedades locales de agave que en un sólo municipio, como en Zapotitlán de Vadillo, puede llegar a ser más de treinta, lo cual constituye una enorme diversificación genética que merece ser valorada y conservada por su importancia para la biodiversidad (Vargas, Zizumbo y Colunga, 2007; Vargas, Zizumbo, Martínez, Coello y Colunga, 2009).

La importancia biocultural de esta región queda de manifiesto porque el occidente de México ha sido una de las principales regiones de Mesoamérica en el contexto de la domesticación y diversificación genética de los agaves mezcaleros, mediante largos procesos de continua selección humana (Colunga y Zizumbo, 2007). Por lo tanto, se considera un área muy importante para la conservación in situ de especies y variedades locales de agave, además de que expresa claramente la importancia de la cultura indígena-campesina en la conservación y mantenimiento de esa diversidad. No obstante, el género agave ${ }^{4}$ ha sido reconocido históricamente por su enorme importancia biológica y cultural, y no sólo por pertenecer actualmente a la cadena productiva agave-mezcal, sino de igual manera por los distintos usos que de forma secular se le ha dado a la planta como alimento, medicina, combustible, ornato, fibra, abono, forraje, construcción, entre otros.

por el hombre americano durante miles de años. México es el área con mayor diversidad en todo el mundo. De un total de 210 especies, México tiene 159, es decir, 75\%, con 119 especies endémicas, esto es, exclusivas de su territorio" (García Mendoza, A., 2012: 4).

${ }^{4}$ La familia de las agaváceas tiene nueve géneros, el más abundante corresponde al género agave con doscientas especies, aproximadamente. Su centro de origen y domesticación está en México donde se pueden observar prácticamente en todos los ecosistemas, aunque son más abundantes en las zonas semiáridas y templadas (García Mendoza, 2004). Los estados biológicamente importantes para la familia agavaceae son Chihuahua, Coahuila, Durango, Jalisco, Puebla, Querétaro, Oaxaca y Sonora. Se presume que estados como Guerrero, Zacatecas y San Luis Potosí mantienen un subregistro de especies que puede ser superado "conforme avance la investigación florística” (ídem: 161). La más biodiversa de las provincias florísticas es la de TehuacanCuicatlán, aunque de todas las provincias fisiográficas de México la que presenta más abundancia de especies de agave es el eje neovolcánico transversal, que se extiende desde el Golfo de México hasta las costas del Pacífico mexicano. 
Los mezcales de la región pertenecen a una amplia tradición que incluso, de acuerdo con varias evidencias arqueológicas encontradas recientemente, puede tener cerca de dos mil o tres mil quinientos años (Zizumbo, González, Olay, Almendros, Flores y Colunga, 2009). Los maestros mezcaleros de la zona tienen por lo menos 430 años produciendo mezcal, como quedó registrado en la Relación de Zapotitlán, que en 1579 ya menciona: "Hay en esta provincia un árbol llamado MEXCATL, que llaman los españoles 'maguey', que dél se hace vino, vinagre, miel, sogas, ropa, madera $\mathrm{p}[\mathrm{ar}] \mathrm{a}$ casas, agujas, clavos, hilo, bálsamo p[ar]a heridas muy aprobado" (Acuña, 1988: 69). En este trabajo se busca poner de relieve la importancia de los productores de mezcal del sur de Jalisco, como un ejemplo exitoso del manejo diversificado de los recursos naturales y como una evidencia de las prácticas agroforestales de los campesinos que permiten "producir conservando y conservar produciendo", mediante una estrategia que articula la dimensión bio-social, bio-productiva y bio-cultural que resulta clave en el manejo y conservación de los agroecosistemas y la biodiversidad.

La importancia de los mezcales tradicionales en el estado de Jalisco ha sido insuficientemente reconocida, sobre todo, por la omnipresencia de la industria tequilera que ha contribuido a la oclusión y marginación del producto al cual le debe su origen: el mezcal. La historia de los destilados de agave en el occidente de México ha cobrado mayor importancia a partir de los estudios realizados por Colunga, Larqué, Eguiarte y Zizumbo (2007), Zizumbo y Colunga (2007), y Valenzuela, Regalado y Mizoguchi (2008), entre otros. Estos autores han discutido la importancia de la región centro-occidente como uno de los principales centros de origen y lugar de difusión de los destilados de agave. Paradójicamente, mientras uno de los objetivos más importantes es educar al consumidor en la importancia de la conservación del patrimonio histórico, cultural y natural respecto al mezcal, el mayor riesgo que corre su producción es la inserción de las bebidas tradicionales en nuevas cadenas de valor.

El ingreso a otra escala de mercado puede provocar un incremento súbito de la demanda que obliga a los productores a optimizar 
o modernizar procesos, a fin de obtener mayores rendimientos, casi siempre a costa de disminuir sustantivamente la calidad de sus productos. Esta tendencia, lejos de favorecer a quienes pertenecen a la cadena, puede aumentar la vulnerabilidad y la dependencia frente a los agentes externos y, en todo caso, parece repetir el mismo fenómeno que ocurrió con la industria del tequila, donde para satisfacer un mercado en crecimiento continuo se han visto obligados a interrumpir el tiempo de maduración de la planta para utilizar agave verde o sin madurar; han modificado drásticamente el periodo de fermentación con el uso de acelerantes químicos para conseguir en horas lo que en la fermentación natural puede durar semanas, y han conseguido una sorprendente laxitud jurídica con su Norma Oficial que les permite adicionar alcohol de caña hasta en $49 \%$, dejando de producir un destilado de agave en sentido estricto.

En el municipio Zapotitlán hay evidencias sobre la continuidad y permanencia de prácticas agroecológicas ancestrales en el manejo de los cultivos antiguos de agave mezcalero que, en este momento, constituyen una de las principales estrategias para defenderse de las constantes crisis que atraviesa el ámbito rural, no sólo porque el manejo diversificado le permite a los productores conservar la multifuncionalidad de la agricultura campesina y la sustentabilidad ecológica, sino porque también dichas prácticas revelan la permanencia de un tipo de agricultura arraigada en sus características culturales que resultan social y económicamente viables en el largo plazo, lo que sin duda provee de mejores condiciones para impulsar el potencial endógeno de sus localidades.

Para demostrar esas afirmaciones se realizó el estudio de caso de los productores de mezcal como un ejemplo de diversidad biocultural en el estado de Jalisco. La investigación ha privilegiado la observación directa y participativa frente a otros métodos de recolección de datos con el fin de conocer con mayor detalle la forma en que los grupos campesinos emprenden sus propias estrategias de desarrollo local. En la primera parte se aborda el contexto de la diversidad biocultural en Jalisco. En un segundo momento se pone de relieve la producción tradicional de mezcal en el sur del estado, a través del caso de la familia Partida Rivera, para finalmente problematizar su importancia en términos de 
la necesidad de proteger y conservar el patrimonio biocultural de los pueblos indígenas y campesinos en el occidente de México.

\section{Diversidad biocultural en Jalisco}

El enfoque biocultural tiene como su principal premisa que tanto a nivel local como global la biodiversidad, junto con la diversidad cultural están estrechamente interrelacionadas. De esta forma, la diversidad biocultural comprende la diversidad de la vida en todas sus manifestaciones biológicas y culturales, incluso se presume que han evolucionado conjuntamente en un complejo sistema de adaptación socioecológico (Maffi, 2007). En dicho vínculo se sustenta la supervivencia de las comunidades campesinas, así como sus estrategias de resistencia ${ }^{5}$ frente a los procesos que impactan negativamente sus formas de subsistencia y que impiden el establecimiento de modalidades propias de desarrollo. Eckart Boege por su parte afirma que el patrimonio biocultural se compone de los:

recursos naturales bióticos intervenidos en distintos gradientes de intensidad por el manejo diferenciado y el uso de los recursos naturales según patrones culturales, los agroecosistemas tradicionales, la diversidad biológica domesticada con sus respectivos recursos fitogenéticos desarrollados y/o adaptados localmente. Estas actividades se desarrollan alrededor de prácticas productivas — praxis - organizadas bajo un repertorio de conocimientos tradicionales —corpus - y relacionando la interpretación de la naturaleza con ese quehacer, el sistema simbólico en relación con el sistema de creencias — cosmos — ligados a los rituales y mitos de origen ... el patrimonio biocultural de los pueblos indígenas se traducirá en bancos genéticos, de plantas y animales domesticados,

\footnotetext{
${ }^{5}$ Sobre todo cuando se apela a la defensa del patrimonio biocultural. Claudio Garibay (2010) ha registrado numerosas evidencias etnográficas sobre la manera en que las comunidades campesinas defienden sus territorios y patrimonios culturales. De hecho, los grupos campesinos en tanto sujeto colectivo organizan el discurso de acuerdo a un lenguaje de patrimonio en el que se representa al territorio, "al paisaje y sus recursos como un bien inalienable en el que se funda una identidad local; un bien por tanto, no negociable" (2010: 180).
} 
semidomesticados, agroecosistemas, plantas medicinales, conocimientos, rituales y formas simbólicas de apropiación de los territorios (Boege, 2008: 13).

La perspectiva biocultural se considera una dimensión estratégica para la conservación y desarrollo sustentable de los pueblos indígenas en países megadiversos, en función de cuatro evidencias principales (Boege, 2008, 2009; Toledo, Alarcón, Moguel, Olivo, Cabrera, Leyequien y Rodríguez, 2001; Toledo et al., 2002): el traslape geográfico entre diversidad biológica y cultural; entre territorios indígenas ${ }^{6}$ y regiones de alto valor biológico; la importancia de los pueblos indígenas como pobladores y manejadores de hábitats bien conservados, y por la existencia de un comportamiento orientado a la conservación de los recursos naturales relacionado con la permanencia de conocimientos, creencias y prácticas.

\footnotetext{
${ }^{6}$ Para Alicia Barabas "el 'territorio' es utilizado tanto por la geografía cultural y por la antropología como un concepto que reúne al espacio con el colectivo, y ha sido entendido como la parte del espacio que una colectividad considera como propio ... Desde mi perspectiva se refiere a los espacios geográficos culturalmente modelados, pero no sólo los inmediatos a la percepción — paisaje — sino también los de mayor amplitud, que son reconocidos en términos de límites y fronteras. La noción de territorio como un espacio propio bordeado de fronteras, por porosas que éstas puedan ser, a veces no existe en el nivel supracomunitario o étnico; en varios grupos las nociones etnoterritoriales han quedado confinadas a los espacios comunitarios. El territorio puede ser definido como espacio culturalmente construido, lo que implica que es valorizado y apropiado simbólica e instrumentalmente por la sociedad" (Barabas, 2004: 149). Por otra parte, Porto Gonçalves considera que "el territorio no es simplemente una sustancia que contiene recursos naturales y una población — demografía-y, así, están dados los elementos para constituir un Estado. El territorio es una categoría espesa que presupone un espacio geográfico que es apropiado y este proceso de apropiación — territorialización — enseña identidades — territorialidades — que están inscritas en los procesos siendo, por tanto, dinámicas y mutables, materializando en cada momento una determinada orden, una determinada configuración territorial, una topología social (Bourdieu, 1989). Estamos lejos pues, de un espacio-sustancia y sí frente a una tríada relacional territorio-territorialidad-territorialización. La sociedad se territorializa siendo el territorio su condición de existencia material. Es preciso recuperar esta dimensión material, sobre todo, en este momento como el que vivimos, en el que se da cada vez más importancia a la dimensión simbólica, casi siempre de modo unilateral, como si lo simbólico se opusiera a lo material" (Porto Gonçalves, 2009: 44).
} 
En el estado de Jalisco, tanto la Sierra de Manantlán como la zona del complejo volcánico de Colima donde se ubica este estudio de caso, son consideradas "zonas de refugio" de la población indígena, pero también zonas de una amplia diversidad biológica expresada en las Áreas Naturales Protegidas declaradas en esa zona. Esta combinación de población originaria y zonas de alta biodiversidad ha permitido una evolución compleja de los agroecosistemas que se observa no sólo en el modo de vida, sino además en el manejo de los recursos, los hábitos alimenticios y en ciertas actividades productivas, como en el caso del mezcal.

La categoría "diversidad biocultural" ha ido ganando terreno en el ámbito académico, pero también ha logrado una mayor centralidad en el discurso de los movimientos indígenas convirtiéndose ahora en una de sus reivindicaciones principales. Este concepto ha servido para reconocer la importancia del vínculo entre diversidad cultural y natural, partiendo de la correlación entre diversidad lingüística y riqueza biológica bajo el supuesto de que el traslape geográfico entre estas dos variables, subraya la importancia de los pueblos indígenas como "principales pobladores y manejadores de hábitats bien conservados" (Toledo et al. 2002: 2). La categoría de diversidad biocultural se observa en todo caso, como "un concepto de conservación simbiótica” en donde la diversidad biológica y la cultural están vinculadas directamente y es necesario reconocer la importancia de su traslape geográfico, no sólo para pensar nuevas estrategias de conservación, sino para superar falsas disyunciones del paradigma desarrollista, desde las que se construyeron dicotomías entre cultura/naturaleza, tradición/modernidad, y otros binarismos que han justificado las ideologías del progreso y el desarrollo.

Un estudio realizado para observar la diversidad biocultural en Jalisco (Tetreault y Lucio, 2011) ha buscado medir el traslape entre los territorios indígenas y las regiones de alto valor biológico, más allá de las dos regiones bioculturales ampliamente reconocidas — Wixárika y Sierra de Manantlán-. El análisis consistió en comparar los 30 municipios que contienen núcleos agrarios denominados "comunidad indígena”, con aquellos 45 que tienen un área reconocida por su importancia ecológica, ya sea Áreas Naturales Protegidas (ANP), 
Regiones Terrestres Prioritarias (RTP), Sitios RAMSAR ${ }^{7}$, o Áreas de Importancia para la Conservación de las Aves en México (AICAS). A pesar de que los polígonos de los núcleos agrarios y los de las áreas de importancia ecológica no necesariamente se traslapan, creemos que la presencia de esos dos elementos en 30 de los 125 municipios del estado es suficientemente relevante porque dicha aproximación representa " $89.43 \%$ del territorio de las comunidades indígenas (692,877 ha) que se encuentra en municipios con ANP, RTP o AICAS” (Tetreault y Lucio, 2011: 181).

Esto nos lleva a suponer que el aprovechamiento sustentable de los recursos basado en el conocimiento ecológico tradicional se convierte en una evidencia de diversidad biocultural por la manera en que la población local ha logrado adaptar sus características culturales - y sus sistemas de producción tradicionales - a las condiciones ambientales, de tal manera que conservan y mantienen la funcionalidad ecológica y la sustentabilidad de sus actividades productivas. El reto que despierta esta reflexión sería el de identificar y diagnosticar los diversos ejemplos que persisten en todas las regiones bioculturales del estado. De ahí la necesidad de ampliar el conocimiento sobre el patrimonio histórico, cultural y natural de los pueblos indígenas y campesinos para conocer la manera en que los sistemas agroecológicos han coevolucionado en función de su diversidad biocultural.

La interacción entre naturaleza y cultura ha generado una co-evolución continua que se arraiga en prácticas y conocimientos ecológicos locales, que así como han permitido a las comunidades campesinas desarrollar estrategias para el manejo diversificado de sus recursos, les han provisto de capacidades especiales con las que preservar el patrimonio biocultural. Esa herencia biocultural descansa no sólo en las estrategias de generación y transmisión del conocimiento, sino de hecho en aquellas prácticas de las comunidades indígenas y campesinas que conforman un complejo sistema socioambiental a través de los vínculos entre territorio, recursos naturales y sus propios lenguajes de valoración sobre la naturaleza y el medio ambiente. La propuesta de reconocer el

\footnotetext{
${ }^{7}$ Convención Relativa a los Humedales de Importancia Internacional especialmente como Hábitat de Aves Acuáticas.
} 
patrimonio biocultural busca también influir en el diseño de política pública en materia de conservación de la biodiversidad, a partir de reconocer la importancia del conocimiento indígena tradicional y, por lo tanto, de la necesidad de incluir la participación de los pueblos indígenas en la aplicación de las estrategias de conservación en el marco de las regiones bioculturales prioritarias para la conservación y el manejo sustentable de los recursos naturales.

Una de las evidencias en donde el aprovechamiento y la conservación de los recursos se han articulado históricamente, puede observarse con la producción de destilados de agave, sobre todo en algunos municipios del sur del estado de Jalisco. El caso de Zapotitlán de Vadillo es de interés particular no sólo por los altos niveles de biodiversidad que están presentes en su territorio, de igual forma por el tipo de prácticas agroecológicas que persisten en la agricultura campesina de la zona.

El municipio de Zapotitlán se localiza en el sur del estado de Jalisco en las estribaciones del Nevado de Colima y se extiende hacia la cuenca del río Armería, tiene una extensión de $480 \mathrm{~km}^{2}$. Dentro de sus fronteras municipales se encuentra una importante Área Natural Protegida denominada "Parque Estatal Bosque Mesófilo Nevado de Colima”. Una cuarta parte de la superficie de esa ANP está dentro del municipio y corresponde a las zonas de la Barranca de Alseseca en el ejido de Zapotitlán y al Borbollón en el ejido San José del Carmen. Zapotitlán combina distintos usos de suelo con bosque predominante en $42 \%$, tiene selva baja en $20 \%$ y $35 \%$ de su territorio se destina a la agricultura, el resto corresponde a pastizal y $0.46 \%$ a la zona urbana. Su clima es cálido y semicálido subhúmedo con lluvias en verano principalmente $(32.67 \%$ y $24.81 \%)$, aunque también es templado subhúmedo en 14.24\% (Inegi, 2009). 
Mapa 1. Zona de estudio.
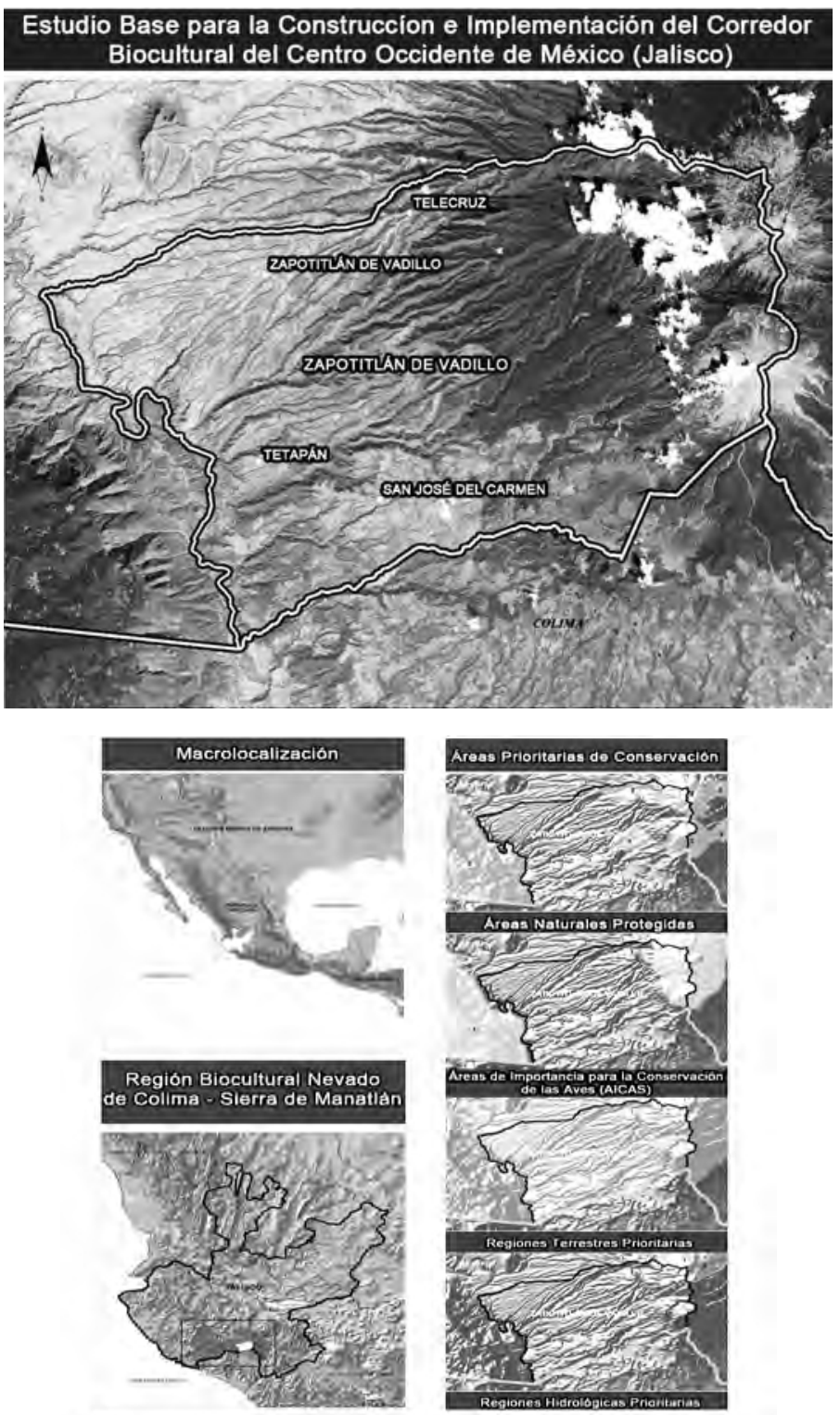

Estudio de Caso

"Zapotitián de Vadillo"

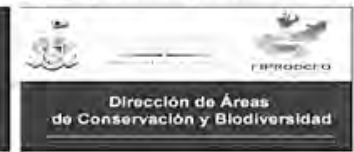


Debido a los distintos pisos ecológicos que existen en el municipio Zapotitlán, el clima cambia de templado a semiseco muy cálido, de acuerdo con las diferencias altitudinales que varían de 3,700 $\mathrm{msnm}$ en la parte occidental del Nevado de Colima a $600 \mathrm{msnm}$ en la zona del río Armería. Los tipos de vegetación van de los bosques de pino-encino, bosque mesófilo, bosque de oyamel, selva baja y pastizal ubicados en su mayoría en la provincia fisiográfica del Eje Neovolcánico y la Sierra Madre del Sur. Tiene una población de 6,685 habitantes, distribuida en 49 localidades, de las cuales 47 tiene 200 habitantes o menos. Sus dos zonas urbanas en la cabecera municipal y en el pueblo San José del Carmen concentran a 3,530 y 770 habitantes, respectivamente. La pobreza moderada está presente en $57 \%$ de la población, mientras que $20 \%$ se encuentra en pobreza extrema. En el municipio Zapotitlán se presenta un índice de marginación medio, aunque en algunas de las principales localidades llega a ser alto, como en las comunidades Chancuellar, Mazatán y La Cruz. Su principal actividad económica sigue siendo la agricultura basada en el cultivo de maíz, frijol y maguey - mezcalero- - aunque las extensiones de agave azul han crecido en los años recientes.

El sur de Jalisco se considera uno de los posibles centros de origen y domesticación de especies y una de las áreas más importantes para la diversificación de las especies de agave mezcalero, mediante procesos continuos de selección y cultivo, no sólo porque ahí está concentrada la mayor riqueza biológica del occidente de México, sino por otras evidencias de tipo arqueológico donde los agaves angustifolia y maximiliana se encuentran representados en ofrendas funerarias que datan de 400-600 d.C. lo que sugiere que ya eran cultivados con fines alimenticios. Las prácticas campesinas en torno a la agricultura tradicional en Zapotitlán de Vadillo, Jalisco, revelan un complejo "conocimiento, uso y manejo de los recursos", como se afirma en Flores (2012), que estructuran una cultura alimentaria con base en el agroecosistema de milpa establecida posiblemente "antes del periodo cerámico temprano 4500 ańos antes del presente” (Flores, 2012: 101).

La continuidad de los usos alimentarios de las especies vegetales en la zona, sobre todo de los agaves y el maíz, desde el periodo "arcaico 
hasta nuestros días indica su alta importancia cultural” a lo largo del tiempo (Flores, 2012: 110). La importancia de los distintos usos dados al agave proviene fundamentalmente de su uso alimentario en el periodo mesoamericano, ya que antes de la domesticación del maíz el agave cocido fue la principal fuente de carbohidratos y, por lo tanto, una de las primeras plantas utilizadas como alimento desde hace por lo menos 9,000 años. En Zizumbo, Flores, y Colunga (2012) se afirma que fue la principal fuente de alimentación para los grupos cazadores-recolectores desde el norte del Istmo de Tehuantepec hasta el río Gila en Arizona, de tal forma que el agave junto con el maíz constituyen el centro de la antigua dieta en Mesoamérica.

Como resultado del primer estudio sobre diversidad biocultural en Jalisco (Tetreault y Lucio, 2011), se identificaron seis regiones bioculturales prioritarias en el estado. Una de ellas es la región del Nevado de Colima-Sierra de Manantlán, donde se han identificado por lo menos cuatro estudios de caso — huertos familiares, café bajo sombra, milpa y mezcal tradicional— relacionados con prácticas de manejo de los sistemas agroforestales que pueden constituir una evidencia sólida de la diversidad biocultural. En el presente estudio de caso se pone atención particular a la producción de mezcales tradicionales en el sur de Jalisco, como un caso ejemplar de manejo campesino de los recursos naturales basado en conocimientos y prácticas tradicionales que respaldan la hipótesis sobre la presencia de la diversidad biocultural en la región.

\section{El caso de la familia Partida Rivera en el municipio de Zapotitlán de Vadillo}

En Zapotitlán de Vadillo hay cerca de 60 productores de mezcal, pero son menos de diez los que cuidan celosamente la producción de esta bebida en el sentido tradicional. Del total de productores, sólo ocho de ellos utilizan formas de producción tradicionales, los demás combinan procesos artesanales y tecnología moderna con una finalidad estrictamente comercial. ${ }^{8}$ La mayoría manejan dos variedades de agave

\footnotetext{
${ }^{8}$ En cuanto a los procedimientos de elaboración del mezcal se pueden distinguir entre los tradicionales y los comerciales. El procedimiento tradicional se ajusta estrictamente
} 
de las especies rhodacantha y angustifolia, conocidos en la zona como ixtero amarillo y lineño. Algunos pueden tener más variedades según el manejo agronómico en cada parcela, con una presencia de entre 2, 7 o 20 tipos de agave, de acuerdo con las observaciones y registros in situ ya realizados.

De los productores tradicionales de mezcal en esta región, destaca la familia del maestro mezcalero Macario Partida, cuya tradición productora se ha transmitido por varias generaciones. La parcela de la familia Partida Rivera se localiza a $4 \mathrm{~km}$ en dirección sur desde la cabecera municipal de Zapotitlán de Vadillo, en los lomeríos cercanos al río Armería-Ayuquila, su altitud es de 964 msnm, y el tipo de vegetación de la zona es selva baja con cactáceas columnares. La semiaridez del terreno y la mayor exposición solar que pueden recibir los agaves al no tener demasiada sombra por vegetación arbórea favorece el crecimiento del agave y, sobre todo, la retención de azúcares que son esenciales para la obtención de alcohol durante la fermentación.

Su forma particular de conservar el sentido tradicional de la elaboración del mezcal, les ha permitido adquirir un prestigio muy especial que ya alcanza el plano nacional e internacional. Esta familia mantiene ciertas prácticas agroecológicas que favorecen la producción de mezcal al enriquecer la diversidad genética del agave con la reintroducción de distintas variedades locales, y al promover su reproducción por semilla y no sólo mediante hijuelos, ${ }^{9}$ además de

al gusto histórico de cada región productora, se utiliza horno de tierra para el cocido, se muele de forma manual, se fermenta de manera natural sin ningún acelerante químico, se usan aparatos de destilación discontinua de barro, cobre, madera entre otros, y su graduación alcohólica está entre 45 y 55\% ALC. VOL. El procedimiento comercial usa normalmente hornos de mampostería, acelera la fermentación con productos químicos y utiliza destiladores de acero inoxidable, todo lo cual altera profundamente la calidad de sus aromas y sabores, además de que tiene baja graduación alcohólica para ajustarlo al gusto del consumidor estándar.

9 El agave tiene tres formas de propagación: la reproducción sexual por semillas, la asexual por la selección de bulbilos que crecen en la inflorescencia o quiote, técnicamente conocida como apomixis y, la tercera, que también es asexual y consiste en la propagación a través de hijuelos o vástagos que crecen alrededor de la planta madre a partir del segundo o tercer ańo de vida. Este último procedimiento es el más generalizado en el cultivo de agave. La vía sexual es poco utilizada porque puede tener un bajo porcentaje de germinación, o porque las plántulas deben permanecer más de 
sembrarlo de tal forma que retiene la humedad y protege el suelo de la erosión. Por otra parte, los Partida han mantenido la calidad orgánica de la bebida al utilizar procedimientos estrictamente naturales en su elaboración y tecnología ancestral, como ocurre con el horno cónico bajo tierra que se usa en la cocción del agave, o con el tipo de destilador que consiste en un alambique de cobre con montera de madera, hecha con un tronco ahuecado conocido como destilador filipino o asiático. ${ }^{10}$

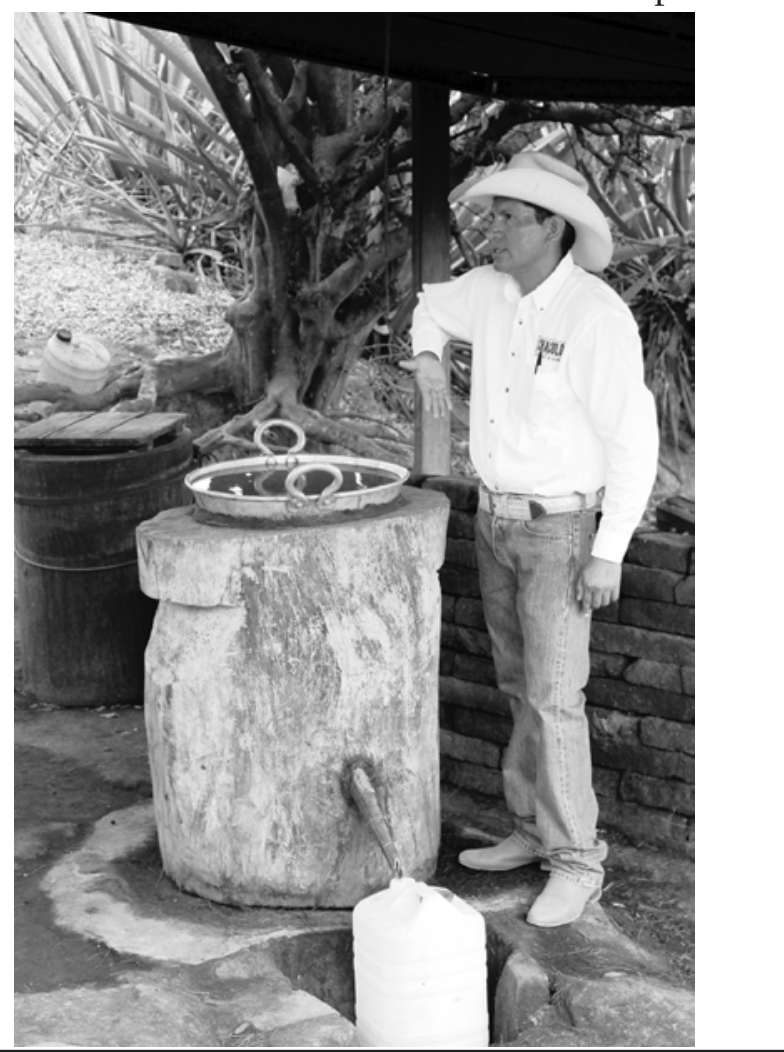

un año en vivero antes de trasladarse a tierra, porque sin el crecimiento necesario serían consumidas por las hormigas. La reproducción por bulbilos es más común en el estado de Oaxaca, en particular con el agave llamado espadín ( $A$. angustifolia).

${ }^{10}$ Colunga y Zizumbo (2007) aseguran que los filipinos traídos por los españoles a las costas de Jalisco y Colima en la famosa Nao de China durante el siglo XVI, introdujeron procedimientos de destilación utilizados para elaborar el vino de cocos, cuya tecnología fue rápidamente apropiada por la población indígena para destilar mezcal, sobre todo porque puede construirse con materiales locales al tener como base un tronco ahuecado. A este tipo de destilador se le conoce como "filipino" o "asiático". 
En su parcela, la familia Partida mantiene cerca de 14,000 plantas de agave, con una densidad media de 2,000 plantas por hectárea. El ritmo de aprovechamiento depende del ciclo de maduración de la planta que de acuerdo con cada variedad puede ir de seis a quince años. El estimado anual de las plantas que alcanzan la madurez y son aptas para la producción de mezcal es cerca de 1,500. Su reproducción se da principalmente por propagación vegetativa, es decir, a partir de los hijuelos que nacen alrededor de una planta madre, aunque recientemente se están implementando técnicas de reproducción por semilla con el fin de mantener y enriquecer la diversidad genética que podría disminuir por causa de la propagación asexual o clonal a través de hijuelos. Otra de las cualidades en el manejo tradicional de los cultivos en la parcela de Partida Rivera es la selección e introducción de agaves de toda la zona de los valles intermontanos que se ubican entre el Nevado de Colima y la Sierra de Manantlán, con el fin de ampliar la escala de aromas y sabores que se obtienen con cada variedad. Con esta práctica han conseguido una mayor diversificación genética de los agaves al propagar y reintroducir más de 20 variedades locales de las dos especies predominantes $A$. angustifolia y $A$. rhodacantha. ${ }^{11}$

Con estas actividades de manejo, la diversidad genética de los agaves domesticados y semi-domesticados se ha incrementado considerablemente, al grado que ha llegado a ser similar a las poblaciones de agave silvestre de la región, según registros de Vargas et al. (2009: 454). El criterio principal de Macario Partida para seleccionar las variedades de agave que reintroduce en su parcela ha sido por el sabor y aroma de la planta. Incluso afirma que todos los agaves que tiene son dulces, "el único más bajito es el [ixtero] amarillo, [pero] todos son dulces, por eso los he traído". Es decir, selecciona cada variedad por el contenido de azúcares percibidos según el gusto o palatabilidad de la planta. También ha decidido propagar el ixtero amarillo, aunque tenga un rendimiento menor al resto de las variedades, porque es el más aromático;

${ }^{11}$ Las variedades de agave señalados por los productores de Zapotitlán son el ixtero amarillo, ixtero verde, azul telcruz, brocha, cenizo, lineño, perempitz, presa grande, verde, cuaquesoca, cuchara, chancuellar, cimarrón, hoja larga, garabato, prieto, manzo, cabresto, palmero, espinoso, pocas hojas, cimarrón verde, cimarrón cenizo y mezcal grande. 
asegura Macario: "rinde menos pero en aromas se los lleva a todos, entonces ahí como que compensa". ${ }^{12}$

Adicionalmente, la importancia del cultivo de agave asociado al sistema tradicional de milpa provee de beneficios añadidos al agrosistema en su conjunto, no sólo por los mayores rendimientos que produce en el cultivo de maíz, a diferencia de las otras parcelas donde no se incluye al agave, sino también por la sostenibilidad agrícola, debido a lo que representan esos cultivos asociados en términos del enriquecimiento de los nutrientes del suelo, retención de humedad y disminución de la erosión por reducción de azolves o escorrentías. $\mathrm{Al}$ ser una zona caracterizada por lomeríos o terrenos con distintos grados de inclinación, el sistema de milpa junto al cultivo de agave reduce erosión, retiene humedad, y ayuda a mejorar la composición de la diversidad edáfica en general. ${ }^{13}$

12 Los productores tradicionales no eligen el tipo de planta que utilizan para la elaboración del mezcal por su rendimiento o por su importancia económica. Si fuera el caso podrían elegir cultivar el agave azul Tequilana Weber cuyo rendimiento es de 5 kg por litro, mientras que los agaves mezcaleros que ellos utilizan están cerca de los 12 o $15 \mathrm{~kg}$ por litro, aunque otros productores de la zona tienen agaves con rendimientos mucho menores, cercanos a los $30 \mathrm{~kg}$ por litro, de tal manera que deciden aprovechar ciertas variedades de agave por el gusto histórico de la zona y no por criterios puramente mercantiles. El gusto histórico, según la Logia de los Mezcólatras se define por "el conjunto de saberes, prácticas, reglas y tradiciones creadas colectivamente a través de la historia, en una región o población y que establecen claramente cómo deben ser las gastronomías locales y, dentro de sus productos, los Mezcales. [...] se podría decir que es la construcción colectiva de los gustos regionales a través del tiempo, que generan reglas de cómo deben saber y oler los Mezcales, cómo deben de elaborarse y cuáles son las pruebas de calidad a que deben someterse para que, en su lugar de origen, sean considerados legítimos, buenos y sabrosos". Cfr. http://www.mezcalpedia.com/ attachments/056_Que\%20es\%20la\%20Logia\%20de\%20los\%20Mezcolatras\%20 MTPM.pdf

${ }^{13}$ La diversidad biológica del suelo o biodiversidad edáfica "contiene algunas de las comunidades más ricas en especies que se conocen, en algunos ecosistemas, el suelo puede contener más de mil especies en poblaciones que pueden alcanzar 1 o 2 millones de individuos por $\mathrm{m}^{2}$. Estos organismos pueden dividirse en tres grandes grupos: bacterias, hongos y animales ... el suelo es un sistema clave en el funcionamiento de los ecosistemas terrestres. En él se llevan a cabo dos procesos vitales: la descomposición y el flujo de nutrientes. Estos procesos son controlados principalmente por la actividad biológica, la cual depende en última instancia de la temperatura y la humedad" (Fragoso et al., 2001: 3). Por otro lado, según Ibáńez y García-Álvarez (2002: 365) "la biocenosis edáfica sensu stricto está constituida mayoritariamente por microorga- 
Macario Partida, con 74 años de vida, recuerda que su primer contacto con la tradición mezcalera se dio cuando siendo apenas un niño le llevaba "de comer" a su abuelo a la taberna. ${ }^{14}$ Más adelante se fue envolviendo en cada proceso relacionado con la producción de mezcal y en primera instancia aprendió a jimar, esto es, a cosechar los agaves cuando llegan a la madurez para cortarles las hojas y prepararlos para su cocción. Con el paso del tiempo tuvo pleno conocimiento de los procedimientos de destilación del mezcal hasta que él mismo se hizo productor, junto con su padre. Comenta que "antes", cuando él era joven, el mezcal se llevaba a la ciudad de Colima en remudas con cargas de hasta 80 litros en cada viaje. El camino duraba doce horas porque salían a las cinco de la mañana y llegaban hasta las cinco de la tarde, aunque "si eras bueno para caminar a las tres [pm] llegabas", comenta Macario. Además recuerda que en aquel tiempo todos vendían lo que sacaban en la primera destilación ${ }^{15}$ a la que le agregaban cinco litros

nismos (bacterias, algas, hongos y protozoos), por la micro y mesofauna, y por algún grupo conspicuo de macrofauna, como es el caso de los lumbrícidos. Según estimaciones actuales el número de especies de bacterias superaría la cifra de 30.000, los hongos incluyen más de 1.500 .000 especies, las algas 6.000, los protozoos $10.000 \mathrm{y}$ los nematodos 500.000 (Hawksworth y Mound, 1991). Otros grupos de la fauna del suelo como colémbolos, ácaros u oligoquetos, también incluyen miles de especies y cada día se describen otras nuevas para la ciencia de todos los grupos mencionados". Las prácticas agroecológicas de los campesinos son un factor clave en el manejo y conservación de la diversidad edáfica, sobre todo por que: 1. Combinan "un gran número de especies y diversidad estructural en el tiempo y en el espacio, mediante la organización tanto horizontal como vertical de los cultivos. 2. Explotan una variedad de microambientes, que difieren en suelos, temperatura, altitud, pendiente, fertilidad, etc., en un campo o en una región. 3. Mantienen ciclos cerrados de materiales y desechos a través de prácticas efectivas de reciclado. 4. Cuentan con una complejidad de interdependencias ecológicas, resultando en cierto grado de supresión biológica de las plagas. 5. Cuentan con recursos locales, mas energía humana y animal, usando pocos insumos externos. 6. Cuentan con variedades locales de cultivos e incorporan el uso de plantas y animales silvestres. La producción es generalmente para el consumo local; así, la influencia de factores no económicos en la toma de decisiones es sustancial" (Altieri y Nicholls, 2000: 257). Cfr: "La biodiversidad del suelo. Su importancia para el funcionamiento de los ecosistemas", disponible en: http://www.inia.uy/Publicaciones/ Documentos\%20compartidos/111219220807164750.pdf

${ }^{14}$ Nombre regional de las pequeñas fábricas de mezcal.

${ }^{15}$ El mezcal de primera destilación tiene menor calidad dado que la pureza de los sabores sólo se alcanza con una segunda o a veces hasta tercera destilación. 
de alcohol puro para hacerlo rendir y lo llevaban a vender a Colima, aunque eso se acabó cuando empezó a salir el "Tonayan". ${ }^{16}$

La tradición productora de Zapotitlán permaneció hasta hace poco tiempo en una condición marginal, o incluso fuera del marco legal, porque los productores de Jalisco se encuentran excluidos de la Denominación de Origen Mezcal (DOM) ${ }^{17}$ Esto implica que la NOM070 que corresponde a la DOM les prohíbe comercializar el producto con el nombre de "mezcal", y los obligue a etiquetarlo como "destilado de agave", algo que incluso está en permanente controversia con la Comisión Federal de Mejora Regulatoria (Cofemer) que pretende constantemente prohibirles el uso de la palabra "agave". ${ }^{18}$ Además, las normas oficiales para bebidas alcohólicas que los regulan suelen ser más rigurosas respecto a las aplicadas para el Mezcal o el Tequila. Para reafirmar la marginación y exclusión de los productores tradicionales, las cargas impositivas de la Secretaría de Hacienda incrementan dramáticamente la problemática anterior, cuando hasta $72 \%$ del valor de cada litro producido corresponde a los impuestos que se deben pagar a la Federación, reduciendo seriamente la viabilidad de esta actividad productiva.

${ }_{16}$ En el contexto de la declaratoria de protección de la Denominación de Origen Tequila en 1974, "los productores tonayenses decidieron reducir sus costos de producción mezclando alcohol de cańa y licor de agave o concentrado de agave, como le nombran, y agua”, estas mezclas buscaron abatir los costos de producción para vender un destilado de muy bajo precio, además de dirigirse a consumidores poco exigentes o de escasos recursos que sin embargo representaron un mercado alternativo al tequila y de consumo masivo (Nuñez, 2011: 140).

17 La norma aplicable al mezcal es la NOM-070-SCFI-1994, publicada el 28 de noviembre de 1994 en el Diario Oficial de la Federación, en la que originalmente se reconocen cinco estados dentro de la Denominación de Origen: San Luis Potosí, Durango, Guerrero, Oaxaca y Zacatecas. Posteriormente se agregó un municipio de Guanajuato en 2001, siete de Tamaulipas en 2003 y 29 de Michoacán en 2012. Cfr. DOF, 22 de noviembre de 2012.

${ }^{18}$ Cfr: Oposición al proyecto de NOM-186 sobre bebidas alcohólicas elaboradas a partir de agaváceas (http://www.uccs.mx/doc/g/nom-186-scfi-2011_es). Sobre el embate más reciente de la Cofemer consultar el Proyecto de Norma Oficial Mexicana PROY-NOM-199-SCFI-2015, "BEBIDAS ALCOHÓLICAS - DENOMINACIÓN, ESPECIFICACIONES FISICOQUÍMICAS, INFORMACIÓN COMERCIAL Y MÉTODOS DE PRUEBA", en: http://www.cofemersimir.gob.mx/expediente/18062/ mir/39173/regulacion/1831956 
En estas condiciones los productores de la región han promovido dos estrategias para no abandonar del todo la producción de mezcal. Una ha sido la disminución de los costos de producción y por lo tanto de calidad, al combinar el destilado de agave con alcohol de cańa para aumentar los rendimientos y garantizar algunos ingresos por su venta a precios muy accesibles; mientras que otros han privilegiado mantener el procedimiento tradicional de elaboración de mezcal para distinguirlo como un producto totalmente orgánico y de alta calidad, con el fin de venderlo con mayor valor agregado y dirigirlo principalmente a consumidores urbanos vinculados con el mercado gourmet y el comercio justo. Adicionalmente, para revertir esa condición de marginalidad ha sido necesario establecer marcos de asociación entre productores para mejorar procesos, amortizar costos y, sobre todo, incrementar los niveles de calidad del producto con el propósito de poder colocarlo en nuevos mercados, más allá de la escala local o regional.

Con ayuda de otros actores involucrados en la cadena productiva, desde consumidores hasta restauranteros, bartenders y distribuidores, los pequeños productores de mezcal en el sur de Jalisco han podido establecer una serie de alianzas con grupos de defensores de los mezcales tradicionales de distintos lugares de la República, para sumar esfuerzos en la preservación de la sustentabilidad de la cadena productiva, trasladar su producción a esquemas de comercio justo y promover el reconocimiento de los destilados de agave como parte del patrimonio biocultural del occidente de México. Asimismo, ha sido muy importante el trabajo con académicos e investigadores que analizaron la producción de mezcal desde el punto de vista histórico, ambiental, arqueológico, además del económico, con el fin de valorizar no sólo al producto sino a los productores, como los verdaderos custodios de un saber-hacer que constituye una parte fundamental del patrimonio cultural material e inmaterial de los mexicanos, y finalmente para establecer redes de consumo responsable y de comercio justo.

En términos cronológicos este cambio comenzó a darse a mediados de la década del año 2000, con la presencia de investigadores que establecieron las primeras alianzas con activistas y defensores de los mezcales tradicionales, y promovieron el mezcal de la región en otras 
ciudades del país como Guadalajara, Colima, Morelia, o la ciudad de México, logrando una proyección nacional de los mezcales producidos en los alrededores del Volcán de Colima.

Una estrategia más reciente ha sido la explotación del potencial turístico de la región ubicada entre la Reserva de la Biósfera de la Sierra de Manantlán y el Parque Nacional Nevado de Colima, cuya belleza paisajística es un elemento clave que se puede aprovechar para atraer visitantes, y explicar in situ el proceso de elaboración del mezcal, bajo procedimientos y técnicas tradicionales que le permitan al consumidor conocer directamente la calidad orgánica del producto y, por supuesto, mejorar las condiciones de venta por el valor agregado de un mezcal $100 \%$ orgánico y tradicional. Con ese fin, se han realizado desde el año 2010 seis degustaciones o sesiones de trabajo sensorial para evaluar los mezcales de Zapotitlán, describir sus características sensoriales y determinar los niveles de aceptación en el consumidor registrando la aceptabilidad del producto por los asistentes.

La preservación de los mezcales tradicionales ha dependido de la reapropiación que hacen de ella las familias productoras, como se refleja en el legado familiar de los Partida. Esto ha sido posible por la combinación de esfuerzos entre productores, académicos y consumidores, y a pesar de los avances en este sentido, los desafíos no dejan de aparecer, sobre todo en un contexto de expansión de la cadena productiva, cuyo ritmo de crecimiento se observa en el volumen de producción que en el año 2013 fue de 2.5 millones de litros frente a los 434 mil que se producían a mediados de la década pasada, según reporta el Consejo Regulador del Mezcal (CRM). ${ }^{19}$

Sin embargo, la viabilidad de la "industria" del mezcal dependerá de los niveles de sustentabilidad que pueda mantener y no de los mercados a donde se pueda expandir. La familia Partida Rivera nos demuestra que las principales acciones para la conservación de la diversidad genética de los agaves, así como de la diversidad cultural y gastronómica que supone la elaboración de los destilados de agave, y que le puedan dar mayor viabilidad a la cadena en el largo plazo, más allá de normas oficiales y denominaciones de origen, no depende del mercado, sino

${ }^{19}$ CRM, 2015: 21. 
de los agricultores tradicionales quienes mantienen los reservorios de germoplasma y son los verdaderos custodios del saber hacer en torno al mezcal tradicional y del gusto histórico que lo caracteriza.

\section{Riesgos y amenazas al patrimonio biocultural}

En este trabajo se ha presentado al mezcal tradicional del sur de Jalisco como un caso ejemplar de diversidad biocultural, porque la selección continua de variedades silvestres y domesticadas de agave ha servido para ampliar la diversidad genética y la disponibilidad de plantas que tienen un ciclo largo de maduración, al grado que constituyen paisajes bioculturales. El crecimiento exponencial de la industria del mezcal en los últimos ańos puede interpretarse como un signo positivo, pero representa para la cadena productiva un conjunto de riesgos y amenazas en términos ambientales que no siempre son valorados en la misma proporción. Las bebidas destiladas de agave pertenecen a una larga tradición histórica que incluso forma parte de la identidad cultural de los mexicanos, sobre todo por algunas de sus bebidas más emblemáticas — tequila, mezcal, sotol y bacanora-. Sin embargo, más allá de las cuestiones relacionadas con las identidades locales o regionales, vale la pena reflexionar sobre la importancia de los mezcales como parte del patrimonio natural y cultural de México.

Como se ha observado claramente con la industria del tequila que privilegió la expansión del agave azul por sus altos rendimientos, todo monocultivo representa una seria amenaza para la diversidad genética, no sólo por el tipo de reproducción de la planta que depende de sus vástagos o hijuelos y por lo tanto mantiene sus mismas características genéticas, sino también por desplazar a las otras plantaciones silvestres o cultivadas de especies de agave, distintas a la indicada por la Denominación de Origen. Esto pone en riesgo a la propia industria del tequila, además de que reduce su viabilidad, al desaparecer las condiciones de sustentabilidad de la cadena productiva que la obligan a recurrir a prácticas ajenas a la normatividad, como utilizar otras especies de agave y/o utilizar plantas procedentes de zonas geográficas distintas a las permitidas por la DO. El caso del tequila es un claro ejemplo para evaluar los efectos de privilegiar a una especie por su 
importancia económica, sin considerar las consecuencias que pueden generar estas prácticas en términos sociales y ambientales. Es decir, el monocultivo desplaza otras especies o variedades locales de agave y reduce agrodiversidad, pero también desplaza conocimientos y prácticas al sustituir el policultivo por los cultivos agroindustriales.

Al considerar que la producción de mezcal es una práctica secular en el sur de Jalisco, cuyos registros existen desde el siglo XVI, hay suficientes evidencias empíricas como para asegurar que en el occidente de México la destilación de agave se originó en las cuencas bajas de los ríos Armeria-Ayuquila y Coahuayana-Tuxpan, utilizando $A$. angustifolia Haw y A. Rhodacantha Trel (Zizumbo y Colunga, 2007). El hecho más importante para demostrar esa afirmación sería la persistencia de cultivares antiguos o tradicionales que contienen entre 20 y 30 variedades locales de agave, como se puede observar hoy día en las parcelas de las distintas localidades del municipio de Zapotitlán de Vadillo. En esa región se ha encontrado una importante diversidad genética a partir de las numerosas variedades locales de agaves mezcaleros, en un valor muy superior al de otras regiones que también son productoras de destilados de agave como la del tequila o la raicilla.

Con todo, lo que interesa señalar con este estudio de caso es la importancia del papel que desempeñan las prácticas agroforestales tradicionales de los actuales grupos campesinos, en la generación y manejo de la diversidad genética de especies utilizadas en las culturas alimentarias y gastronómicas de la región, en particular aquellas relacionadas con los agaves mezcaleros. Se trató de poner de relieve la importancia de las especies de agave por los múltiples usos que se le han dado a la planta desde el periodo prehispánico y, sobre todo, destacar la importancia actual en términos económicos y culturales que adicionalmente tienen un alto valor en el plano ambiental por ser un recurso clave en el manejo agroecológico de los sistemas productivos, resultado de su potencial en la conservación de suelos, y su capacidad para retener humedad o limitar la erosión, incluso cuando son utilizados como linderos o cercos vivos.

El abandono de prácticas agrícolas sustentables y su reemplazo por una agricultura intensiva basada en nuevos paquetes tecnológicos ha 
generado una dependencia creciente de los insumos que emplea la cadena productiva y la pérdida de agrobiodiversidad por privilegiar cultivos comerciales que, en el mejor de los casos, reducen el papel de los productores a meros maquiladores, o provocan mayores tasas de migración por la intensidad de la crisis que vive el campo desde hace décadas. En esas condiciones es muy difícil mantener aquellas prácticas que se reproducen por costumbre o tradición, pero que favorecen la conservación de la biodiversidad; por eso justamente consideramos que las prácticas agrícolas encontradas en Zapotitlán son un bastión cultural que debe preservarse. En ese contexto, la producción de mezcal en el sur de Jalisco ha sido hasta el día de hoy una actividad económica que produce beneficios muy importantes en el plano social y ambiental, por su valor para la conservación de los recursos naturales y por la preservación de la agrobiodiversidad, además por ser uno de los aspectos centrales del patrimonio cultural inmaterial del estado.

Esta investigación se suma a un proceso de reflexión y sensibilización social iniciado desde hace casi diez años, en torno a la defensa de los mezcales tradicionales de los pueblos de México, en donde se busca el reconocimiento de los destilados de agave no sólo por su valor gastronómico, sino además por su relevancia socioambiental, al ser una actividad productiva fundamental dentro de la agricultura tradicional de numerosos pueblos indígenas y campesinos que tiene una relación directa con la conservación de los recursos biológicos colectivos, sobre todo por el tipo de manejo de la diversidad biológica en todos sus niveles: "germoplasma, poblaciones, especies, ecosistemas y agroecosistemas" (Larson y Neyra, 2004: 4).

\section{Conclusiones}

Como observan Toledo y Barrera-Bassols los sistemas agroecológicos son un componente fundamental en la conservación del patrimonio biocultural, y "el camino más apropiado para mantener y enriquecer la diversidad genética y paisajística”. ${ }^{20}$ Finalmente, con este estudio de caso se buscó demostrar la importancia histórica, social y ambiental de la producción de destilados de agave en el sur de Jalisco, además de

${ }^{20}$ Toledo, V. M. y Barrera-Bassols, 2008: 201. 
reconocer que la diversidad biocultural puede ser preservada mediante el desarrollo de "capital social para poder desarrollar capital natural y pensar que la calidad no sólo está en el producto, sino en las prácticas de producción y su relación con el ambiente". ${ }^{21}$

Un objetivo adicional en este trabajo fue el de contribuir a la orientación de políticas públicas en las zonas de influencia de las ANP o de aquellas áreas de interés, en el marco de la construcción del Corredor Biocultural del Occidente de México, cuya meta es la de "conservar los ecosistemas y su biodiversidad mediante el aprovechamiento sostenible de los mismos". ${ }^{22}$ Se puede afirmar que sin los apoyos necesarios para preservar esas prácticas agroecológicas, que desafortunadamente ya son residuales en un contexto de "nueva ruralidad", en la que los agricultores ya no viven solamente de la agricultura y donde el tipo de manejo agroecológico de los recursos naturales responde más bien a la "tradición" o la "costumbre", será más difícil revertir la pérdida de agrodiversidad y sus consecuencias, en torno a la preservación de sistemas agroalimentarios complejos.

Con el presente estudio de caso se quiso demostrar que la condición actual de los recursos fitogenéticos es resultado del manejo diversificado de los agricultores tradicionales, quienes mediante procesos de selección continua de cultivares tradicionales de agave mezcalero han conservado una amplia base genética del recurso, a diferencia de los procedimientos industriales donde se reduce esa diversidad en extremo al privilegiar el uso de una sola variedad como el $A$. tequilana, o el espadín (A. angustifolia).

En este sentido, los mezcales son un claro reflejo de largos procesos de intervención y adaptación humana al medio ambiente. Demuestran una parte de la antigua interacción entre naturaleza y cultura, esto constituye un verdadero proceso de transformación biocultural

${ }^{21}$ Carrillo, Op. Cit., p. 49.

22 "Acuerdo de colaboración que celebran la SEMARNAT por conducto de la CONANP y el gobierno del estado de Aguascalientes, Guanajuato, San Luis Potosí, Nayarit, Jalisco, Michoacán y Zacatecas para conservar y manejar sustentablemente las áreas naturales protegidas, ecosistemas prioritarios y la biodiversidad, a través de la creación de un Corredor Biocultural en el Centro Occidente de México”.

22 de octubre de 2012 . 
del territorio. La conservación de los mezcales dependerá más de la preservación de los sistemas de producción tradicionales que de la normatividad vigente representadas por las denominaciones de origen. En el plano normativo, no existe una legislación que proteja el saber-hacer de aquellos productores tradicionales cuyas prácticas, además de mantener una tradición ancestral, han revelado la importancia del manejo agroecológico diversificado para favorecer el mantenimiento y conservación de la biodiversidad.

\section{Bibliografía citada}

Altieri, M. y C. Nicholls, 2000, Agroecología: Teoría y práctica para una agricultura sustentable, PNUMA, México, D.F.

Acuña, René, 1988, Relaciones geográficas del siglo XVI: Nueva Galicia, UNAM, México, D.F.

Barabas, Alicia, 2004, "La construcción de los etnoterritorios en las culturas indígenas de Oaxaca", Desacatos, primavera-verano, núm. 14, pp. 145-168.

Boege, E., 2008, El patrimonio biocultural de los pueblos indigenas de México, INAH/CDI, México, D.F.

Boege, E., 2009, "El reto de la conservación de la biodiversidad en los territorios de los pueblos indígenas", en J. Sarukhan, Capital natural de México, vol. II: Estado de conservación y tendencias de cambio, Conabio, México, D.F., pp. 603-649.

Carrillo, Lauro, 2007, "Los destilados de agave en México y su denominación de origen", CIENCIAS, núm. 87, pp. 41-49.

Colunga, P., 2006, Base de datos de nombres técnicos o de uso común en el aprovechamiento de los agaves en México. Centro de Investigación Científica de Yucatán AC. Informe final SNIBCONABIO proyecto No. CS007, México, D.F., en http:// www.conabio.gob.mx/institucion/proyectos/resultados/ InfCS007.pdf

Colunga, P., A. Larqué, L. E. Eguiarte y D. Zizumbo (editores), 2007, En lo ancestral hay futuro: del tequila, los mezcales y otros agaves, 
Centro de Investigación Científica de Yucatán, A.C./Conabio, México, D.F.

Colunga, P., D. Zizumbo y J. Martínez, 2007, “Tradiciones en el aprovechamiento de los agaves mexicanos: una aportación a la protección legal y conservación de sus diversidad biológica y cultural”, en Colunga, P., A. Larqué, L. E. Eguiarte y D. Zizumbo (editores), En lo ancestral hay futuro, del tequila, los mezcales y otros agaves, Centro de Investigación Científica de Yucatán, A.C./Conabio, México, D.F., pp. 229-248.

Colunga, P. y D. Zizumbo, 2007, "El tequila y otros mezcales del centro-occidente de México: domesticación, diversidad y conservación del germoplasma”, en Colunga, P., A. Larqué, L. E. Eguiarte y D. Zizumbo (editores), 2007, En lo ancestral hay futuro, del tequila, los mezcales y otros agaves, Centro de Investigación Científica de Yucatán, A.C./Conabio, México, D.F., pp. 113-131.

Faba, P. y A. Aedo, 2003, "La destilación del tuchi entre los huicholes de Tateikita (San Miguel Huaistita)", en Jauregui, J. y J. Neurath (coordinadores), Flechadores de estrellas. Nuevas aportaciones a la etnología de coras y huicholes, INI, México, D.F., pp. 161-178.

Flores, A., 2012, El paisaje en la cazuela: cultura alimentaria de Zapotitlán de Vadillo, Jalisco, Tesis de licenciatura en Biología, Departamento de Biología, Universidad de Guadalajara.

Fragoso, C. et al., 2001, "La importancia de la Biota Edáfica en México", Acta Zoológica Mexicana, núm. esp. 1, pp. 1-10.

García Mendoza. A., 2004, “Agavaceas”, en García Mendoza, A. M. Ordoñez y M. Briones (coordinadores), Biodiversidad de Oaxaca, UNAM, México, D.F., pp. 159-169.

García, Mendoza. A. 2012, “México, país de magueyes”, La Jornada, 18 de febrero de 2012, p. 4, Suplemento La Jornada del Campo.

Garibay, Claudio, 2010, "Paisajes de acumulación minera por desposesión campesina en el México actual”, en Delgado Ramos, Gian Carlo (coordinador), Ecología política de la minería en América Latina, UNAM, México, D.F., pp. 133-182. 
Ibañez, J. J. y A. García-Álvarez, 2002, “Diversidad: biodiversidad edáfica y geodiversidad”, Edafología, vol. 9, núm. 3, pp. 329-385.

Inegi, 2009, "Prontuario de información geográfica municipal de los Estados Unidos Mexicanos. Zapotitlán de Vadillo, Jalisco. Clave geoestadística 14122”.

Larson, Jorge y Kucila Neyra, 2004, "Recursos biológicos colectivos", Biodiversitas, núm. 53, marzo, pp. 2-14.

Maffi, L., 2007, "Biocultural Diversity and Sustainability", en Pretty, Jules et al. (editores), The SAGE Handboock of Environment and Society, SAGE Publications Ltd, Trowbridge, pp. 267-278.

Nuñez Hernández, Alfonsina, 2011, La construcción de nichos alternos en el mercado de las bebidas espirituosas en México: los licores de agave de Tonaya sin la protección de la Denominación de Origen Tequila, ni Mezcal, Tesis de maestría en Antropología Social, CIESAS-Occidente, Guadalajara, Jalisco, febrero de 2011.

Porto Gonçalves, Carlos Walter, 2009, Territorialidades y lucha por el territorio en América Latina. Geografía de los movimientos sociales en América Latina, Editorial IVIC, Caracas.

Tetreault, Darcy y Lucio, Carlos, 2011, "Diversidad biocultural en el estado de Jalisco. Pueblos indígenas y regiones de alto valor biológico", Espiral, vol. XVIII, núm. 51, pp. 165-199.

Toledo, V. M., P. Alarcón, P. Moguel, M. Olivo, A. Cabrera, E. Leyequien y A. Rodríguez, 2001, "El atlas etnoecológico de México y Centroamérica: fundamentos, métodos y resultados", Etnoecología, vol. 6, núm. 8-9, pp. 7-41.

Toledo, V. M., P. Alarcón, P. Moguel, M. Olivo, A. Cabrera, E. Leyequien y A. Rodríguez, 2002, "Biodiversidad y pueblos indios en México y Centroamérica”, Biodiversitas, núm. 43, pp. 1-8.

Toledo, V. M. y N. Barrera Bassols, 2008, La memoria biocultural. La importancia ecológica de las sabidurías tradicionales, Icaria Editorial, Barcelona.

Valenzuela, Ana G., A. Regalado y M. Mizoguchi, 2008, "Influencia asiática en la producción de mezcal en la costa de Jalisco. El 
caso de la raicilla", México y la cuenca del Pacífico, vol. 11, núm. 33, pp. 91-116.

Vargas, O., D. Zizumbo and P. Colunga, 2007, "In Situ Diversity and Maintenance of Tradicional Agave Landraces Used in Spirits Production in West-Central Mexico", Economic Bonaty, Vol. 4, núm. 61, pp. 362-375.

Vargas, O., D. Zizumbo, J. Martínez, J. Coello and P. Colunga, 2009, "Diversity and Structure of Landraces of Agave Grown for Spirits under Traditional Agriculture: A Comparison with Wild Populations of A. Angustifolia (Agavaceae) and Commercial Plantations of A. Tequilana”, American Journal of Botany, vol. 2, núm. 96, pp. 448-457.

Zizumbo, D. y Colunga, P., 2007, "La introducción de la destilación y el origen de los mezcales en el occidente de México", en Colunga, P. et al (editores), En lo ancestral hay futuro: del tequila, los mezcales y otros agaves, CICY/Conabio, México, D. F. pp. 85-112.

Zizumbo, D., y P. Colunga, 2008a, "Early coconut distillation and the origins of mezcal and tequila spirits in west-central Mexico". Genetic Resources and Crop Evolution, vol. 4, núm. 55, pp. 493-510.

Zizumbo, D. y P. Colunga, 2008b, "El origen de la agricultura, la domesticación de plantas y el establecimiento de corredores biológico-culturales en Mesoamérica", Revista de Geografía Agrícola, núm. 41, pp. 85-113.

Zizumbo, Daniel, F. González, A. Olay, L. Almendros, P. Flores and P. Colunga., 2009, "Distillation in Western Mesoamerica before European Contact”, Economic Botany, vol. 4, núm. 63, pp. 413-426.

Zizumbo, D., A. Flores, and P. Colunga, 2012, “The Archaic Diet in Mesoamerica: Incentive for Milpa Development and Species Domestication”, Economic Botany, vol. 4, núm. 66, pp. 328343. 
Zizumbo, D., A. Flores, and P. Colunga, 2014, "The food system during the Formative Period in West Mesoamerica", Economic Botany, vol. 1, núm. 68, pp. 67-84.

\section{Documentos}

Consejo Regulador del Mezcal, 2015, “Informe 2015”, en http://www. crm.org.mx/PDF/popup/informe.pdf

Diario Oficial de la Federación, DOF, 1974, "RESOLUCION por la que se otorga la protección prevista por el capítulo X de la Ley de la Propiedad Industrial vigente, a la denominación de origen 'Tequila', para aplicarse a la bebida alcohólica del mismo nombre”, 09 de diciembre de 1974, p. 15.

Diario Oficial de la Federación, DOF, 1994, "RESOLUCION mediante la cual se otorga la protección prevista a la denominación de origen Mezcal, para ser aplicada a la bebida alcohólica del mismo nombre", 28 de noviembre de 1994, p. 27.

Logia de los Mezcólatras, Tríptico, "Mezcales tradicionales de los pueblos de México", en http://www.mezcalpedia.com/ attachments/056_Que\%20es\%20la\%20Logia\%20de\%20 los\%20Mezcolatras\%20MTPM.pdf [fecha de consulta: agosto de 2015]. 